\title{
Difficulties and Countermeasures of First Aid Knowledge's Popularized Education for College Students
}

\author{
Xueshuang $\mathrm{Li}^{1, \mathrm{a}^{*}}$ and Xiaoyan Pang ${ }^{1, \mathrm{~b}}$ \\ ${ }^{1}$ Hospital of Wuhan University of Technology, Wuhan 430070, China \\ a903809242@qq.com, b674268410@qq.com \\ *The Corresponding author
}

\begin{abstract}
Keywords: College students; First aid knowledge education; Issues; Countermeasures
\end{abstract}
\begin{abstract}
The popularity rate of first aid knowledge is one of the most important indicators to measure the level of modern civilization in a country. In colleges and universities, popularizing first aid knowledge is of great practical significance to improve students' awareness of emergency response and disaster self-help ability. This paper expounds the current situation of the popularization of first aid knowledge among college students, and analyzes the predicament of the popularization of first aid knowledge education for college students. Wuhan University of Technology is taken as an example to describe the countermeasures of the popularization of first aid knowledge education among college students from three aspects. 1) To enhance students' interest in first aid knowledge's popularized education from relying on diversified carriers; 2) to build three-dimensional emergency resources and broaden the ways of education; and 3) to formulate multi-level contents and to promote educational effect of first aid knowledge. Finally, we summarize the effectiveness of first aid knowledge education for college students.
\end{abstract}

\section{Introduction}

Accidental injury is contingent, sudden and unpredictable. It has now become a global public health problem that is harmful to human health. The statistics show that about 1 million people in China die of various accidental injuries each year. Because of the very low penetration rate of first aid knowledge, $70 \%$ of the patients are not effectively rescued in the "prime time" after they suffer injuries, thereby causing serious consequences or even loss of life. The popularity rate of first aid knowledge is one of the important criteria for measuring the degree of modernization of a country. In recent years, unexpected incidents in China have gradually increased, but the popularity of emergency knowledge is still at a low level. Therefore, China's "2011-2015 National Health emergency Training Plan" clearly disseminates the objective of public health emergency knowledge, which is, to reach $80 \%$ coverage rate of urban residents, $60 \%$ of rural residents. However, due to the lack of public awareness of first aid knowledge, which is far from meeting the expected effect and target of emergency training. College students are a large group of young people who are curious, athletic and adventurous. However, the first aid skills of college students are somewhat lacking, and the level of first aid knowledge needs to be improved urgently [1]. Combining with practical investigation results, some experts and scholars put forward the provision of first aid courses [2-3], the establishment of network platform [4], first aid knowledge lectures [5], the promotion of first aid certificate examination system [6] and other ways to popularize first aid knowledge among college students. These measures are conducive to help students scientifically dispose accidental injuries, and to effectively reduce or avoid the harm and loss caused by unexpected incidents. Community-based first aid training is the collaborative development of locally relevant emergency response training [7]. The training led to significant improvement in first aid knowledge and skills of intervention drivers [8]. Happell et al present a discussion of the potential role of Mental Health First Aid training in undergraduate mental health nursing education [9]. Katona et al provided evidence that a WFA training course in South Sudan is efficacious [10]. Therefore, it is of great practical significance to popularize first aid knowledge education among college students, which is helpful in 
reducing or alleviating the injury of emergencies, and improving the students' health emergency consciousness and disaster self-help ability.

\section{The Current Situation of First Aid Knowledge's Popularized Education for College Students}

About 3.5 million people died of various types of accidents every year in the world, that is to say, every 10 seconds there is a dead man. First aid knowledge and first aid skills are particularly prominent in the role of sudden accidents, since they can provide a barrier for life at the scene of an emergency, thereby saving lives and reducing the degree of injury in the first place. Many countries and regions have treated spreading and mastering the knowledge of first aid as a compulsory course. For example, in Japan, the literacy rate of first aid knowledge among middle school students reaches more than $90 \%$. The popularity rate of first aid knowledge in Germany reaches upon $80 \%$. The proportion of people who have received training for cardio-pulmonary resuscitation in Sweden reaches 45\%, compared to 1/3 in the United States. At the same time, the US stipulates that police, firefighters, teachers and students in large and medium schools must undergo the training for cardio-pulmonary resuscitation and on-site rescue. In Australia, more than 50\% of the population has received training for out-of-hospital first aid.

In recent years, with the promoted attention and publicity of emergency knowledge by the government and all circles, the popularization of first aid knowledge has achieved remarkable results. Domestic universities have strengthened first aid knowledge's popularized education for students through various ways and carriers. In 2012, the first aid course was officially included in the open class at Peking University and it was also the first time that an emergency course was popularized among college students. The Red Cross Society of Fudan University organized emergency teams to take charge of first aid training for students. Central South University participated in the organization of first-aid large-scale "flash" public activities, and vigorously popularized pre-hospital emergency knowledge. Chongqing University, in conjunction with the Chongqing Red Cross, aimed to popularize first aid knowledge for students by organizing the activity named "Training in first aid knowledge and skills for college students", and awarded certificates for qualified students. Wuhan University of Technology presented the first-aid knowledge lecture as a required course in the matriculation education for freshmen, and organized volunteer service team to disseminate and popularize first aid knowledge into communities. Jishou University utilized elective courses to provide first-aid training for non-medical students. Suzhou Vocational Health College carried out first aid knowledge's popularized education through the online course named "basic knowledge and techniques of first aid".

However, there is still a big gap between the popularization of first aid knowledge in China and education abroad, and the former has not yet reached the requirements and standards of modern society for first aid skills among college students. First aid knowledge's popularized education for college students is facing several problems. Firstly, the attention paid by universities is not enough; very little knowledge about first aid has been integrated into the teaching system or taken as a compulsory content of health education for students in the process of personnel training. Secondly, the mastery of first aid knowledge among college students rests on the initial stage 'See first aid knowledge', but the operation stage 'Use first aid knowledge' has not been really implemented. The participation in first-aid training is still not enough, resulting in the lack of practical skills in emergency rescue. Thirdly, the acquisition approach of first aid knowledge for college students is somewhat single. They usually obtain scattered knowledge through television, news, and internet while more knowledge is obtained in the form of lectures. The inclination of active learning among students is not strong, and their learning time is always short, resulting in poor effects.

\section{The Predicament of First Aid Knowledge's Popularized Education for College Students}

Weak Awareness of First Aid Among College Students. In many sudden, critical, severe or even accidental injuries, watching crowd often appears near the accidental sites. Sometimes even the second accident is likely to be caused by watching people's photographing or viewing. All these incidents are the consequences of weak first aid awareness. College students generally have a strong sense of social 
responsibility, but in emergencies, they often lack proper initiative in emergency treatment and regard that rescuing injured people is the duty of medical professionals. On the other hand, college students consider that the probability of accidental occurrence is pretty low and it is impossible for them to be injured by accidents. Therefore, the lack of understanding of the fatalness of accidental harm as well as self-help and mutual aid is common among college students. In addition, a large number of students have little cognition about rapid and effective on-site rescue, which can save the lives of patients and reduce the disability. They distrust in their first aid skills, feel afraid of paying the fiddler, and lack humanitarianism in healing the wounded and rescuing the dying. These indicated above are the direct manifestations of the lack of first aid knowledge among contemporary college students, indicating the deficiency of popularized education of first aid knowledge for college students. Therefore, it is a prominent problem for college health education to promote college students' first aid awareness.

Lack of First Aid Knowledge Among College Students. First aid is a systematic engineering of disaster emergency response, involving many aspects, such as accidental scene evaluation, emergency treatment measures, and emergency coordination management and so on. First aid knowledge relates to medicine, psychology, sociology and behavioral science and many other fields, including not only the care for the injured, but also the assessment of the rescue environment as well as ensuring the implementation of correct ambulance under safe conditions. Because college students do not attach enough importance to the emergency education and there are few ways to obtain first aid knowledge, it is difficult to master relevant first aid knowledge systematically, and some limitations still exist in the understanding of first aid knowledge (shown in Table 1). For common accidental injuries, such as sports trauma, drink suffocation, food poisoning, and heatstroke, many college students have not yet master the basic method of first aid; and first aid knowledge of critical illness, traffic accidents, natural calamities and other unexpected disasters is more insufficient.

Table 1 First aid questionnaire for college students

\begin{tabular}{|l|l|l|l|l|}
\hline Project & $\begin{array}{l}\text { First } \\
\text { commonsense }\end{array}$ & $\begin{array}{l}\text { aid } \\
\text { handaging }\end{array}$ & Fixed handling & $\begin{array}{l}\text { Cardio-pulmonar } \\
\text { y resuscitation }\end{array}$ \\
\hline Male & $82.6 \%$ & $47.3 \%$ & $52.5 \%$ & $38.1 \%$ \\
\hline Female & $85.9 \%$ & $58.6 \%$ & $49.2 \%$ & $41.7 \%$ \\
\hline
\end{tabular}

Weak Skills of First Aid Among College Students. For college students, it is not enough to know only the first aid knowledge. Only by effectively improving the first-aid skills at the scene can they cope calmly and deal with unexpected incidents quickly. The suddenness and complexity of first aid makes the first-aid work challenging and uncertain. In the first aid knowledge's popularized education, forms of lectures, video preaching and knowledge column are generally taken. However, due to the large number of participated students and the lack of training time, the popularized education pays too much emphasis on first-aid theoretical knowledge but overlooks the practical skills. First aid norms and points are not mastered systematically, leading to the unsatisfactory application of first aid knowledge among college students. For those students who lack social experience, they are usually at a loss when they encounter the acute symptoms of some common diseases, which can be life-threatening if they are not handled properly. Because of the weak first aid skills, college students are often powerless to in the sudden accident. Therefore, it is impossible for them to avoid non-standard first aid operations and unscientific first aid treatment, greatly influencing the quality and effect of first aid treatment in the "first time".

\section{The Countermeasures of First Aid Knowledge's Popularized Education for College Students}

Relying on Diversified Carriers to Enhance the Interest of First Aid Knowledge's Popularized Education. Universities and college students have been aware of the importance of first aid knowledge. In order to ensure the effect of first aid knowledge's popularized education, we should firstly improve the learning interest of first aid knowledge among college students. We relied on campus network, 
Wechat platform, campus radio, publicity columns and other carriers, in order to launch scientific popularization and publicity of first aid knowledge and create a good atmosphere and environment for first aid knowledge's popularization. In addition, we utilized the "first aid class meeting" to discuss relevant first aid knowledge and to analyze and exchange all kinds of emergency problems encountered in daily life, aiming to strengthen the learning autonomy of college students. We also held the "first-aid knowledge contest for college students" in order to strengthen the first-aid consciousness and spirit of college students, and to improve the emergency response ability of college students. Meanwhile, we actively promoted "first aid knowledge into the classroom" activities through first aid knowledge seminars, aiming to popularize emergency knowledge and skills in the form of combining theory and practice. We also carried out "please come in" activities, that is, to direct students to the school hospital to participate in emergency knowledge training, focusing on improving on-site exercises and emergency skills for students. Especially in the "World Health Day" and "World Emergency Day" and other major festivals, we organized large-scale "first aid special events", hoping to vigorously promote the general knowledge and importance of first aid, and to cultivate college students' life-saving awareness and first aid consciousness, as well as to enhance students' sense of responsibility and mission for first-aid active learning.

Setting Up Three-Dimensional Resources to Broaden the Ways of First Aid Knowledge's Popularized Education. In order to adapt to the learning styles and educational characteristics of contemporary college students, the health care workers have focused on the development of first aid knowledge's popularized courseware and materials, and have compiled emergency brochures, small video clips and other resources for college students. Through the image, voice, video and other forms of multimedia, based on the advantages of network platform and Wechat platform, the health care workers have constructed multi-layer and three-dimensional resources of college emergency education, aiming to make education means more diverse and make the education practice more flexible. Breaking through time and space constraints, online theoretical learning and off-line practice are combined for students to browse first aid knowledge and relevant information by using personal computer or mobile phone, broadening the new ways for popularizing first aid knowledge. In addition, with the combination of texts and videos, emergency knowledge can be popularized more vividly. For example, in the student activity center, canteens and other places, several first-aid exhibitions have been held covering natural hazards, public emergencies, accidental injuries and other topics of first aid knowledge. First aid knowledge is easier for college students to understand with the combination of images and real activities as well as the combination of interpretations and operations. The school allocated special funds to purchase emergency resources of the education of first aid knowledge and to implement the first-aid equipment configuration, including "Resusci Anne", tourniquet, elastic bandage, and other emergency equipment. More attention has been paid contrapuntally and effectively to the first aid knowledge's popularization of kidney function of college students, in order to achieve an organic unity of the training and the practical needs of emergency.

Formulating Multi-Level Contents to Enhance the Effectiveness of First Aid Knowledge's Popularized Education. In order to enhance the effect of first aid knowledge's popularization, the university hospital formulated different scientific and reasonable training courses for students of different grades, developed multi-level emergency thematic contents and carried out the popularization of first aid knowledge in different subjects and different stages (Table 2). In the new stage of enrollment, first aid and public health lectures are mainly carried out to enhance the awareness and responsibility of first aid for freshmen. Moreover, daily first-aid common sense is popularized for students to avoid possible coma, shock and other accidents in military training. In the sophomore stage, students should mainly master the prevention and treatment of untoward effect in sports, as well as first-aid methods and techniques of common sports injuries. In the junior stage, aiming at the experimental training of science and engineering colleges and universities, the school hospital usually popularizes emergency treatment and preventive measures for burn and scald in chemistry experiments, high temperature and high pressure (hthp) experiments. In the senior stage, the first-aid techniques for natural disasters such as traffic accidents, fires, earthquakes, typhoons and floods are disseminated. Meanwhile, before the 
summer vacation, summer emergency topics are preached for students, including the knowledge about preventing drowning, fire, and heatstroke. And students are supposed to master on-site emergency measures of heatstroke and drowning. On the "World Emergency Day", the training and simulated demonstration activities of bare-handed cardio-pulmonary resuscitation are provided for college students with the field experience of first aid knowledge.

Table 2 Subject contents of first aid knowledge's popularized education

for college students

\begin{tabular}{|c|c|c|c|}
\hline Time & Lecture topics & Relevant contents & Participants \\
\hline Freshman year & $\begin{array}{l}\text { Awareness and } \\
\text { commonsense of } \\
\text { first aid }\end{array}$ & $\begin{array}{l}\text { Enhance the awareness of first aid; } \\
\text { mastery of first-aid measures in } \\
\text { military training and basic knowledge } \\
\text { of first aid. }\end{array}$ & Freshmen \\
\hline Sophomore year & $\begin{array}{c}\text { First aid about } \\
\text { sports trauma }\end{array}$ & $\begin{array}{l}\text { Four rescue techniques (hemostasis, } \\
\text { bandaging, fixation and removal) }\end{array}$ & $\begin{array}{l}\text { Sophomore } \\
\text { students }\end{array}$ \\
\hline Junior year & $\begin{array}{l}\text { First aid about } \\
\text { experimental } \\
\text { training }\end{array}$ & $\begin{array}{l}\text { First aid treatment and prevention of } \\
\text { burns, scalds, and cutting injuries; } \\
\text { disposal and emergency treatment of } \\
\text { field injuries (insects or animal bites, } \\
\text { etc.) }\end{array}$ & Junior students \\
\hline Senior year & $\begin{array}{l}\text { Knowledge and } \\
\text { techniques of first } \\
\text { aid }\end{array}$ & $\begin{array}{l}\text { Rescue of common critical } \\
\text { emergency; first aid of traffic } \\
\text { accidents and natural disasters. }\end{array}$ & Senior students \\
\hline $\begin{array}{l}\text { Before summer } \\
\text { vacation }\end{array}$ & $\begin{array}{l}\text { Summer vacation } \\
\text { first aid }\end{array}$ & $\begin{array}{l}\text { Knowledge about avoiding drowning, } \\
\text { fire, and heatstroke; mastery of on-site } \\
\text { first-aid treatment. }\end{array}$ & $\begin{array}{l}\text { All college } \\
\text { students }\end{array}$ \\
\hline $\begin{array}{l}\text { On the "World } \\
\text { Emergency Day" }\end{array}$ & $\begin{array}{l}\text { Demonstration and } \\
\text { operation of fist aid }\end{array}$ & $\begin{array}{l}\text { Skills training and simulated } \\
\text { demonstration of cardio-pulmonary } \\
\text { resuscitation }\end{array}$ & $\begin{array}{l}\text { All college } \\
\text { students }\end{array}$ \\
\hline
\end{tabular}

\section{Summary}

Both the management departments of universities and college students have gradually realized the importance and urgency of the popularization of first aid knowledge, which is helpful to create a good atmosphere and environment for the popularization of first aid knowledge. In the activities of popularizing first aid knowledge, the enthusiasm of college students to participate in active learning is continuously improved, and the effect of first aid knowledge's popularization is remarkable. The popularization rate of first aid knowledge for students is up to $86.5 \%$ at graduation. Incident rate among college students is greatly reduced, especially the scientific and reasonable training contents have helped students obtain the systematic knowledge of first aid, improved students' on-site aid skills, and enhanced students' awareness of self-protection and social emergency service ability.

It is helpful to promote the public safety and harmonious stability of campus by completing the popularized education of first aid knowledge for college students. Although many colleges and universities have a certain understanding of first-aid training work for students, the overall degree of attention still needs to be improved. Training should not be remained at the theoretical level; instead it must be implemented to everyone at a practical stage. Through the social public training projects, colleges and universities should establish an emergency training system and formed a set of standard first-aid training process and mode, to promote the standardization and normalization of first aid knowledge's popularized education. In order to solve the problem of inadequate teaching staff of first aid training, it is an effective way to set up online courses to popularize first aid knowledge. 


\section{References}

[1] X.Y.Wang. Analysis of current situations of first aid knowledge among college students and the effect of disaster reduction education [J]. Journal of Qilu Nursing. 20 (2014) 71-72. (In Chinese)

[2] Y. H. Huang. Countermeasures of the popularization of on-site first aid knowledge for college students [J]. Chinese Journal of Clinical Rational Drug Use., 5(2012) 173-175. (In Chinese)

[3] L.Y. Zhong, X. J. Qiu, G. L. Zhong. Investigation and analysis of the present situation of first aid knowledge and skill among non-medical college students in Shenyang [J]. Journal of Hunan Normal University (Medical Science). 13(2016): 139-142. (In Chinese)

[4] X.L. Cong, Y. Yang, S. F. Xu. Teaching practice of first aid knowledge sharing class for college students based on QQ network [J]. Chinese Nursing Research. 29 (2015) 3149-3151. (In Chinese)

[5] B. Guo. Current situation and analysis of the mastery of basic first aid knowledge and skills among college students in Gansu Province [J]. Health Vocational Education. 34 (2016) 118-119. (In Chinese)

[6] G. L.Wang, X.H. Dai. A study of training in first-aid knowledge and skills for non-medical college students [J]. Journal of Southwest China Normal University (Natural Science Edition). 37(2012) 152-156. (In Chinese)

[7] D. VanderBurgh, R. Jamieson, J. Beardy, S. D. Ritchie, A. Orkin. Community-based first aid: a program report on the intersection of community-based participatory research and first aid education in a remote Canadian Aboriginal community [J]. Rural and Remote Health. 14(2014)

[8] A. O. Olumide, M. C. Asuzu, O. Kale. Effect of First Aid Education on First Aid Knowledge and Skills of Commercial Drivers in South West Nigeria [J]. Prehospital and Disaster Medicine. 30 (2015): 579-585.

[9] B. Happell, R. Wilson, P. McNamara. Undergraduate mental health nursing education in Australia: More than Mental Health First Aid [J]. COLLEGIAN. 22(2015) 433-438.

[10]L. B. Katona, W. S. Douglas, S. R. Lena, K. G. Ratner, D. Crothers, R. L. Zondervan, C. D. Radis. Wilderness First Aid Training as a Tool for Improving Basic Medical Knowledge in South Sudan. Prehospital and disaster medicine, 30(2015) 574-578. 